\title{
COMPARACIÓN DE DIFERENTES TECNICAS PARA MANEJO DEL DOLOR POSTOPERATORIO EN REEMPLAZO TOTAL DE RODILLA
}

Rinaldi Leonardo Ivan ${ }^{1}$, Roland Horacio ${ }^{1}$, Passadore María Eugenia ${ }^{1}$

1 Asociación anestesia, analgesia y reanimación de Córdoba. Argentina.

Introducción: A pesar de las nuevas técnicas para manejo del dolor postoperatorio, más del $50 \%$ de pacientes sometidos a procedimientos traumatológicos, como reemplazo total de rodilla (RTR), no logran obtener controles adecuados del dolor.Muchos son mayores de 65 años con diferentes comorbilidades. Para evitar eventos adversos postquirúrgicos, es importante el control del dolor.

Objetivo General: Comparar 3 técnicas utilizadas para manejo del dolor postquirúrgico de RTR, en el Hospital Privado de Córdoba.

Material y Métodos: Trabajo retrospectivo, transversal. Realizamos una búsqueda sistemática en pacientes de ambos sexos, entre 50-85 años, sometidos a RTR entre 05/2010-04/2016, en el Hospital Privado de Córdoba. Criterios de inclusión: Pacientes entre 50-85 años, ambos sexos, ASA I-III, bajo anestesia raquídea (AR) sometidos a RTR. Criterios de exclusión: Pacientes $<50$ y $>85$ años, consumo de aines o corticoides, alergia a medicamentos utilizados, y quienes no recibieron AR para RTR. Se incluyeron 88 pacientes: AR realizada con bupivacaina hiperbara $0,5 \% 15 \mathrm{mg}+$ Fentanilo $10 \mathrm{mcg}$, espacio L3/L4. Premedicación: Diclofenac $75 \mathrm{mg}+$ Dexametasona $8 \mathrm{mg}$. Categorizamos en 3 grupos según técnica empleada; G0: bomba de infusión continua de morfina + aines. G1: AR con opioides + aines. G2: bloqueo nervio femoral ecoguia- do acceso inguinal + aines. Datos recolectados: EVN en reposo y movimiento las primeras $24 \mathrm{~h}$, consumo de opioides, incidencia de reacciones adversas (RA).

Resultados: N: 88 pacientes, $(42 \%$ hombres, $58 \%$ mujeres), 19 incluidos en G0 (21,5\%), 31 en G1 (35\%) y 38 en G2 (43\%). Media de edades: 70 años. En G1, 100\% presento buen manejo del dolor $(\mathrm{EVN}<4)$ en postquirúrgico inmediato (6 h postquirúrgico), G2: 81,58\% y G0: 42,11\%. Relación estadística significativa (p: 0,000002 ) Esto se mantiene en las $12 \mathrm{~h}$ del postquirúrgico aunque sin significancia estadística. Sin embargo, esta asociación pierde relevancia a las $24 \mathrm{~h}$ de postquirúrgico (G0: efectividad $80 \%, \mathrm{G} 1: 73 \%$ y G2: 71\%), referido al EVN en reposo, aunque en EVN en movimiento a las 24 h, sólo G1 supera el $50 \%$ de efectividad. Complicaciones: en G1 $39 \%$ náuseas/vómitos, $23 \%$ Prurito y $3 \%$ depresión respiratoria sin ARM. G0 requirió rescates de morfina en $47 \%$ y G2 en $37 \%$.

Conclusiones: Hubo variaciones en el manejo del dolor según el protocolo utilizado durante las primeras $24 \mathrm{~h}$. Sólo se encontró relación estadísticamente significativa en postquirúrgico inmediato a favor del G1. Luego de $24 \mathrm{~h}$, persiste diferencia a favor del G1, aunque sólo supera el $50 \%$ de efectividad. Se debería optimizar el manejo del dolor a las 24 h combinando 2 o más métodos analgésicos. 